\title{
Aplicação do Kaizen para redução do número de reclamações de clientes em uma indústria de aço cortado e dobrado
}

\author{
Application of Kaizen to reduce the number of complaints in a cut and folded up steel \\ industry
}

\section{Silvio Romero Cavalcanti de Souza Junior (B) orcid.org/0000-0001-5727-2427}

\author{
Luis Cordeiro de Barros Filho (iD) orcid.org/0000-0001-5727-2427
}

E-mail do autor principal: Silvio Romero Cavalcanti de Souza Junior silvioromero88@hotmail.com Resumo

Atualmente, o setor da construção civil faz uso de várias alternativas para o fornecimento de aço. Dentre outras vem se destacando a indústria do aço cortado e dobrado. O corte e dobra de vergalhões é realizado em um parque de máquinas bastante específico e tem como objetivo fornecer o material seguindo as especificações de cada projeto, dentro das normas brasileiras regulamentadoras (NBR). Não obstante todo processo de Controle da Qualidade, durante a manufatura podem ocorrer algumas inconsistências/variabilidades que impactam diretamente na satisfação dos clientes. Para medir essa quantidade de insatisfações é utilizado um indicador denominado de tonelada por ocorrências (t/RC). Visando melhorar esta satisfação ou reduzir a insatisfação foi utilizado a prática de Método de Análise e Solução de Problemas (MASP) com objetivo de reduzir o número de reclamações dos clientes. Com a formação da equipe do projeto, todos os passos foram seguidos: identificação do problema, observação, análise, plano de ação, ação, verificação, padronização e conclusão. Finalmente foram alcançados resultados demonstrando a eficiência e a eficácia do MASP através da implementação de melhorias planejadas, resultando na melhoria da satisfação dos clientes.

Palavras-Chave: construção civil, aço cortado e dobrado, satisfação dos clientes, MASP.

\begin{abstract}
Currently, the construction industry makes use of several alternatives for steel supply. Among others, the cut and folded up steel industry stands out. The cutting and bending of rebar is carried out in a very specific machinery park and aims to provide the material according to the specifications of each project, within the Brazilian regulatory standards (NBR). Notwithstanding all Quality Control processes, during manufacturing some inconsistencies / variabilities may occur that directly affect customer satisfaction. To measure this amount of dissatisfaction, an indicator called ton per occurrence ( $t / R C)$ is used. In order to improve this satisfaction or reduce dissatisfaction, the practice of Analysis and Problem Solving Method (MASP) was used in order to reduce the number of customer complaints. With the formation of the project team, all steps were followed: problem identification, observation, analysis, action plan, action, verification, standardization and completion. Finally, results were achieved demonstrating the efficiency and effectiveness of MASP through the implementation of planned improvements, resulting in improved customer satisfaction.
\end{abstract}

Key-words: civil construction, cut and folded up steel, customer satisfaction, MASP. 


\section{Introdução}

Com o atual crescimento da sociedade, é impossível idealizar o mundo sem o uso do aço. A produção desse material é um forte índice do estágio de crescimento econômico de uma nação, pois seu consumo aumenta proporcionalmente à construção de edifícios, fabricação de veículos, instalação de meios de comunicação, implantações de fontes de energias e produção de equipamentos domésticos e industriais. Esses produtos já se tornaram comuns em nosso cotidiano, mas para fabricá-los, cada vez melhorm devemos sempre prospectar novas técnicas.

O mercado atual vive um período de grande avanço tecnológico, que exige que as empresas mantenham alto nível de flexibilidade e de inovação em seus processos. As exigências do mercado aliadas ao aumento da concorrência fizeram com que o ciclo de produção tivesse como uma das suas premissas a redução de custos e com que a atividade das empresas passasse a ser sustentável dos pontos de vista financeiro, social e ambiental. Para serem competitivas, as empresas investem em ativos permanentes, buscando aumentar seu volume de produção [1].

Os indicadores de satisfação dos clientes, são monitorados nas organizações, a análise e monitoramento dos dados são muito importantes, pois focam na manutenção e fidelidade dos clientes. Neste contexto, qualquer esforço para alavancar o grau de satisfação será benquisto dentro de qualquer organização. Com a aplicação do método de análise e solução de problemas espera-se aumentar o nível de satisfação dos clientes nesta indústria de aço cortado e dobrado.

\section{Indústria de aço cortado e dobrado}

As indústrias de aço cortado e dobrado realizam a transformação de vergalhões em barras ou rolos sob medida, de acordo com as especificações do projeto de estrutura eliminando uma etapa demorada e muito trabalhosa nos canteiros de obra.

\subsection{Processo de corte e dobra}

O processo de corte e dobra é resultado da transformação, em meio fabril, de aço em rolos (bobinas) e ou barras retas em diversos itens de formatos especificados em projetos de estrutura, na quantidade exata, de acordo com as normas da ABNT 6118 e 7480 para a composição das peças estruturais de determinado empreendimento.

Algumas vantagens desse processo são: Eliminação de uso de bancadas para preparação das armações; Redução das perdas por sobra de pontas e extravios; Diminuição do capital de giro, pois os fornecimentos são realizados de acordo com o cronograma da obra; dentre outros.

Os diâmetros mais comuns utilizados na construção civil são $5 \mathrm{~mm}, 6,3 \mathrm{~mm}, 8 \mathrm{~mm}, 10 \mathrm{~mm}$, $12,5 \mathrm{~mm}, 16 \mathrm{~mm}, 20 \mathrm{~mm}, 25 \mathrm{~mm}$ e $32 \mathrm{~mm}$. Algumas empresas produtoras de aço cortado e dobrado trabalham com aço em bobinas com bitolas de até 20 $\mathrm{mm}$, sendo que, para a produção de diâmetros maiores, utilizam barras retas (comprimento de até $14,5 \mathrm{~m})$.

A transformação do aço se divide em pequenos processos, como se pode observar na figura 1:

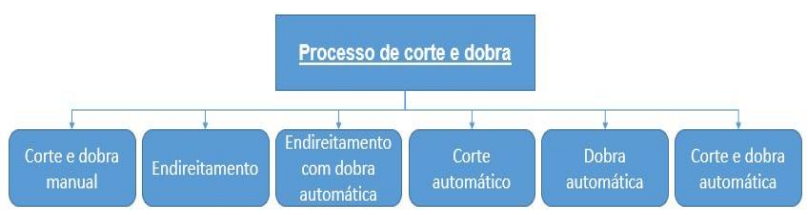

Figura 1: Processo de corte e dobra Fonte: [2]

Corte Manual: Neste processo, o abastecimento, a medição das barras e o acionamento do equipamento para efetuar o corte são realizados pelo operador. No corte manual, podem ser cortados vergalhões em barras retas de diversos comprimentos e várias bitolas. [2]

Dobra Manual: O posicionamento das barras a serem dobradas é realizado pelo operador. O processo manual facilita a produção de vergalhões com dobras e dimensões diferenciadas, pois o operador pode comandar o movimento da máquina de acordo com o tempo de comando e posicionar as barras conforme o formato desejado. [2] 


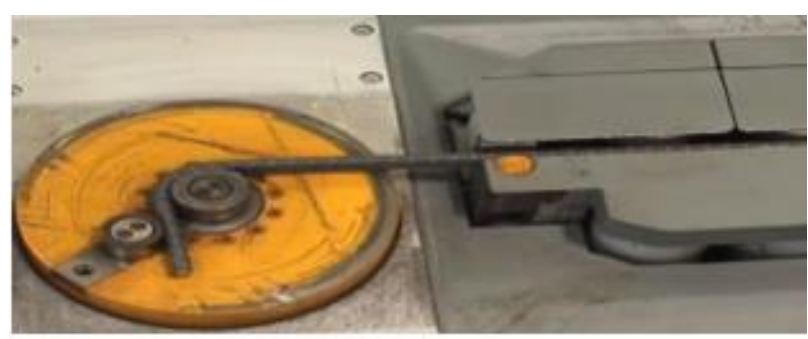

Figura 2: Mecanismo de dobra Fonte: [2]

Endireitamento: Nesse processo, as máquinas endireitam e cortam o material que vem das usinas siderúrgicas em forma de bobinas como matéria prima. As máquinas funcionam automaticamente, necessitando que os operadores abasteçam e programem os comprimentos de barras que serão cortados, de acordo com a solicitação do cliente. Existem dois tipos de endireitamento: por roletes ou por guias rotativas que giram em alta rotação. [2]

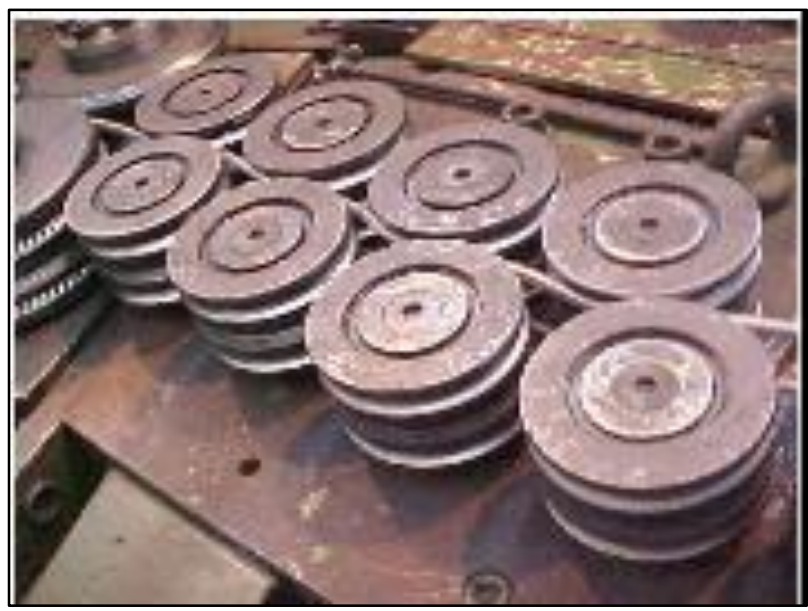

Figura 3: Conjunto de roletes endireitadores Fonte: Acervo do autor

Endireitamento com dobra automática: As bobinas são endireitadas e dobradas automaticamente, não necessitando passar para um próximo processo de Corte e Dobra. O abastecimento e o acompanhamento da produção dos formatos, além da programação do equipamento, são de responsabilidades do operador. [2]

Corte automático: As máquinas cortam automaticamente as barras retas que vem como matéria prima das usinas e os operadores devem abastecer o equipamento e programar quantidades e comprimentos das peças que deverão ser cortadas. [2]

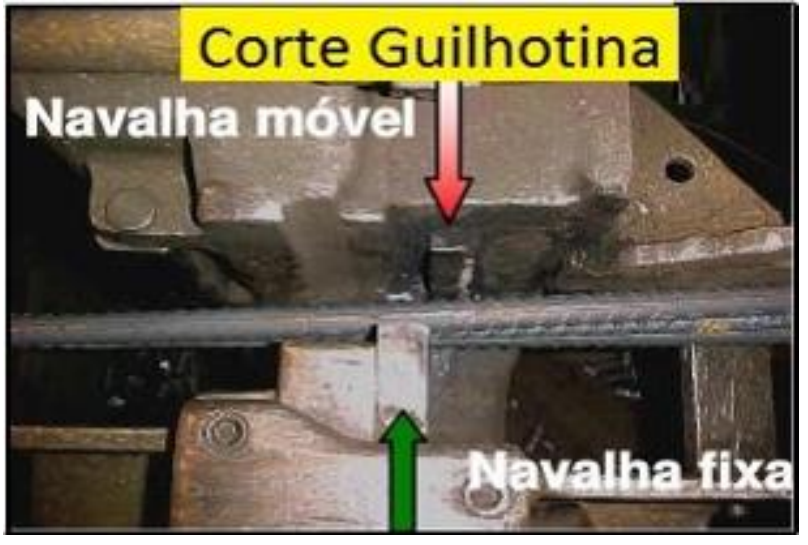

Figura 4: Mecanismo de corte Fonte: Acervo do autor

Dobra automática: $O$ abastecimento do equipamento, normalmente, é realizado através de uma esteira intermediária do corte automático ou por ponte rolante. $\mathrm{O}$ operador programa o equipamento e a dobra são realizados de forma automática. [2]

Corte e dobra automático: A matéria prima que vem das usinas siderúrgicas são barras que são cortadas e dobradas automaticamente. O corte e Dobra automático pode ser considerado um dos processos mais avançados, tecnologicamente. Os equipamentos deste processo são compostos por duas telas de programação: uma para a dobra e outra para o corte. Os operadores precisam abastecer e programar os formatos que serão cortados e dobrados. [2]

\section{Marco teórico}

\section{$3.1 \quad$ PDCA}

É uma ferramenta da qualidade utilizada no controle do processo para a solução de problemas (PDCA). Apresenta quarto fases: P ("Plan": Planejar): seleção de um processo, atividade ou máquina que necessite de melhoria, com medidas claras para obtenção de resultados, D ("Do": fazer): implementação do plano elaborado e acompanhamento de seu progresso, C ("Check": verificar): análise dos resultados obtidos na execução do plano e, se necessário, avaliação do plano, A ("Act": agir): caso tenha obtido sucesso, o novo processo é documentado e se transforma em um novo padrão.

http://dx.doi.org/10.25286/repa.v4i1.887 


\subsection{PDCA de Melhoria - Kaizen}

O "Kaizen" foi criado no Japão após a II Guerra Mundial pelo engenheiro Taichi Ohno, com a finalidade de reduzir os desperdícios gerados nos processos produtivos, buscando a melhoria contínua da qualidade dos produtos e o aumento da produtividade. A palavra "Kaizen" significa "melhoria contínua". "Kai" significa mudar e "Zen" significa perfeição. Atualmente é considerado como uma ferramenta de melhoria contínua da qualidade, da tecnologia, dos processos, da cultura da empresa, da produtividade, da segurança e da liderança. O "Kaizen" está baseado na eliminação de desperdícios com base no bom senso, no uso de soluções baratas que se apoiem na motivação e criatividade dos colaboradores para melhorar a prática de seus processos de trabalho, com foco na busca pela melhoria contínua. É um sistema que engloba todos os funcionários da empresa, onde eles podem dar sua opinião a fim de melhorar algo em qualquer ambiente da empresa [3].

O método de análise e solução de problemas (MASP) é um caminho ordenado, composto de passos e sub-passos pré-definidos para a identificação de um problema, análise de suas causas, determinação e planejamento de um conjunto de ações que consistem em propor uma solução eficaz, a verificação do resultado da solução e posteriormente a realimentação do processo a geração do aprendizado e da possível replicação. O MASP prescreve como um problema deve ser resolvido e não como ele é resolvido, contrapondo dois modos de tomada de decisão que Bazerman [4] denomina de modelo prescritivo e modelo descritivo. O MASP segue o primeiro modelo e por esse motivo é também definido como um modelo racional. Partindo também do pressuposto de que toda solução trás em si um custo associado e um valor intangível associado, a solução que se pretende descobrir é aquela que maximize os resultados, minimizando os custos e consequências envolvidos. Portanto, um ponto ideal para a solução, em que se pode obter o maior benefício para o menor esforço, o que pode ser definido como decisão ótima [4].

Solucionar um problema é melhorar o resultado ruim até um nível razoável, ou então superar as melhores práticas existentes, ou seja, tornar-se o "Benchmark".

As causas do problema são investigadas levandose em consideração os fatos e a relação de causa e 36 efeito, analisada com bastante precisão. Decisões sem fundamentação, baseadas na imaginação ou em teorias de gabinete devem ser totalmente evitadas, pois tentativas de resolver problemas baseando-se nesse tipo de decisão leva a direções erradas, causando fracasso ou atraso na melhoria. $O$ ataque ao problema deve ser planejado e implementado um método adequado de maneira a impedir o reaparecimento dos fatores causadores do problema [2].

Os oito passos do MASP, apresentados na figura 5, devem ser dados para resolver um problema:

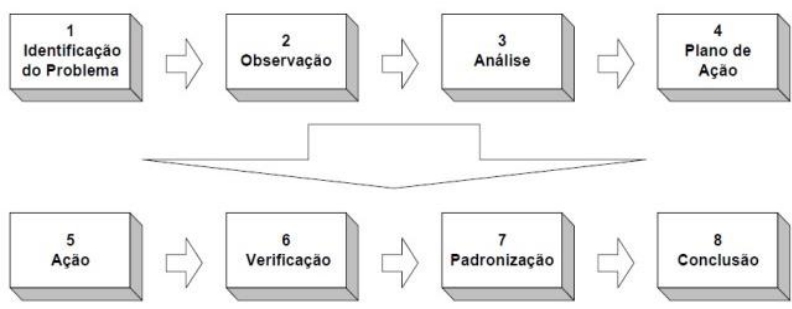

Figura 5: Oito etapas do MAPS Fonte: [2]

Se estas oito etapas forem entendidas e executadas nesta ordem, as atividades de melhoria terão consistência lógica e as vantagens serão cumulativas.

\subsubsection{Oito etapas do MASP}

O método de solução de problemas é constituído por oito importantes processos, onde cada uma das etapas contém diversas tarefas, conforme destrinchados na tabela 1 .

Tabela 1: Método de análise e solução de problemas.

\begin{tabular}{|c|c|l|}
\hline \multicolumn{2}{|c|}{ MAPS - Método de Análise e Solução de Problemas } \\
\hline $\mathbf{1}$ & Identificação & $\begin{array}{l}\text { Escolha e detalhe o problema que se } \\
\text { deseja resolver. }\end{array}$ \\
\hline $\mathbf{3}$ & Observação & $\begin{array}{l}\text { Observe bem o problema, quando } \\
\text { acontece e quando não. Anote tudo que } \\
\text { puder. }\end{array}$ \\
\hline $\mathbf{4}$ & Análise & $\begin{array}{l}\text { Analise e compare tudo que você } \\
\text { observou. Quanto mais esforço você } \\
\text { dedicar a essa parte, maiores as chances } \\
\text { de sucesso. }\end{array}$ \\
\hline & $\begin{array}{l}\text { Faça um plano para que o que causou o } \\
\text { problema não volte a ocorrer. }\end{array}$ \\
\hline
\end{tabular}




\begin{tabular}{|c|c|l|}
\hline $\mathbf{5}$ & \multicolumn{1}{|c|}{ Ação } & Execute o seu plano. \\
\hline $\mathbf{7}$ & Verificação & $\begin{array}{l}\text { Volte a observar o problema, se ele } \\
\text { continuar ocorrendo, volte para o passo } \\
2 .\end{array}$ \\
\hline $\mathbf{8}$ & Conclusão & $\begin{array}{l}\text { Tento resolvido o problema, transforme } \\
\text { o novo método de fazer em um hábito ou } \\
\text { uma rotina, assim, o problema não } \\
\text { ocorrerá mais. }\end{array}$ \\
\hline $\begin{array}{l}\text { Reflita sobre o que aconteceu e tente } \\
\text { lembra-se de outros problemas que } \\
\text { podem ser evitados com a mesma ação. }\end{array}$ \\
\hline
\end{tabular}

Fonte: [5]

\section{Etapa 1 - Identificação do Problema:}

Essa etapa deve definir claramente o problema e reconhecer sua importância, elaborar o histórico do problema e para chegar a este ponto deve-se fazer o levantamento em termos concretos, considerando somente os resultados indesejáveis de baixo desempenho. Também deve-se demonstrar qual é a perda de desempenho nas condições atuais e quanto precisa ser melhorado, designar de forma oficial uma pessoa para liderar a solução do problema. Para obter melhores resultados nessa etapa, deve-se seguir as recomendações a seguir:

- Usar o maior número de dados possíveis para identificar o problema mais importante. Justificar as razões que levaram à sua escolha, agregando valor à necessidade de resolvê-lo;

- Esclarecer a importância da solução do problema escolhido para que as pessoas reconheçam e trabalhem com seriedade para resolvê-lo, pois do contrário elas dedicarão esforços parciais ou até abandonarão o processo no meio do caminho;

- Não tentar descrever as causas e propor ações corretivas durante a etapa de Identificação do Problema, isto será feito mais tarde, durante a etapa de Análise. Procurar descrever os resultados do problema (efeitos/consequências) e a sua relação com a perda de desempenho ou a perda monetária, em geral associada;

- Estabelecer bases ou valores-alvo reais e tangíveis que possam ser alcançados, até mesmo de forma parcelada (em etapas). Por exemplo, uma fração defeituosa de $0 \%$ em um processo industrial é cientificamente impossível de ser alcançado;

- Definir metas econômicas (ou ganhos) na solução do problema é de extrema importância para a 37 organização, pois deve-se maximizar a utilização dos recursos financeiros disponíveis. A economia mensal, resultante da solução de problemas e implementação de melhorias de forma proativa, reverterá em recursos para investir em melhores condições de trabalho e inovação tecnológica ao seu processo;

- Caso necessário, dividir o problema em parcelas que possam ser tratadas eficazmente, onde, na maioria das vezes, será possível encontrar agilidade em descobri causas e resolvê-las. A motivação gerada na solução de uma parte do problema dará um impulso forte na condução do trabalho evitando que as pessoas dispersem do foco da solução;

- Estabelecer um prazo (data-limite) para solução do problema e, a partir deste, um cronograma claramente definido. A falta destas referências temporais indicará que não há prioridade em resolver o problema, ou seja, de nada adiantou esclarecer a importância da sua solução.

\section{Etapa 2 - Observação:}

Nessa etapa a equipe do projeto deve investigar as características especificas do problema, utilizando-se de uma visão sistêmica, inicialmente sob quatro pontos: tempo, local, tipo e sintoma. Em seguida, deve observar outros pontos de vistas para descobrir variações nos resultados. Todas essas observações devem ser realizadas pela equipe responsável no local de trabalho.

Para obter melhores resultados nessa etapa, deve seguir as recomendações descritas abaixo:

- Investigar o problema sob vários pontos de vista e ter um entendimento completo de todas as suas características. Nesta etapa, não se deve atentar para as causas da ocorrência do problema, deve-se apenas olhar o problema como ele se apresenta. À primeira vista, isto parece a etapa anterior (problema). É comum confundir estas duas etapas, mas seus objetivos são totalmente diferentes. O objetivo da etapa 1, identificação do problema, é reconhecer a importância do problema; o objetivo da etapa 2 , observação, é descobrir fatores que são causas do problema;

- As pistas para resolução de um problema estão no próprio problema. A variação em um resultado, em geral, é seguida pela variação nas causas e há a possibilidade de existir uma relação entre elas;

http://dx.doi.org/10.25286/repa.v4i1.887 
- Independente de qual seja o problema deve-se observálo através das quatro visões importantes: Tempo, Local, Tipo e Efeito. Ainda assim, estes enfoques não são suficientes, deve-se buscar mais alternativas e jamais se contentar com as possibilidades esgotadas em relação aos resultados e seus efeitos;

- Especial atenção deve ser dada aos dados e estes devem ser buscados no local de origem. Esquecer a postura de resolver problemas no escritório e ir ao local colher dados, falar com as pessoas, observar a ocorrência no exato momento que estão acontecendo. A tabela 2 mostra um exemplo de ferramenta utilizada nessa etapa.

Tabela 2: Folha de verificação

\begin{tabular}{|c|c|c|c|c|c|}
\hline \multicolumn{3}{|c|}{ Componente: Conjunto ABC } & \multicolumn{3}{|c|}{ Seção: Linha de Montagem } \\
\hline \multicolumn{3}{|c|}{$\begin{array}{c}\text { Processo de trabalho: } \\
\text { montagem }\end{array}$} & \multicolumn{3}{|c|}{$\begin{array}{l}\text { Data da Produção: } \\
30 / 03 / 05\end{array}$} \\
\hline \multicolumn{3}{|c|}{$\begin{array}{c}\text { Quantidade Produzida: } \\
1000 \text { peças }\end{array}$} & \multicolumn{3}{|c|}{ Inspetor: José Antonio } \\
\hline $\begin{array}{l}\text { Tipos de } \\
\text { Defeitos }\end{array}$ & $\begin{array}{c}\text { Freq. } \\
\text { do } \\
\text { Item }\end{array}$ & \multicolumn{2}{|c|}{ Class } & $\begin{array}{c}\% \\
\text { Individual }\end{array}$ & $\begin{array}{c}\% \\
\text { Acumulada }\end{array}$ \\
\hline $\begin{array}{l}\text { Parafuso } \\
\text { Solto }\end{array}$ & 68 & \multicolumn{2}{|c|}{10} & $33,5 \%$ & $33,5 \%$ \\
\hline Sujeira & 41 & \multicolumn{2}{|c|}{$2^{\circ}$} & $20,2 \%$ & $53,7 \%$ \\
\hline Riscos & 29 & \multicolumn{2}{|c|}{$3^{\circ}$} & $14,3 \%$ & $68,0 \%$ \\
\hline Solda & 21 & \multicolumn{2}{|l|}{$4^{\circ}$} & $10,3 \%$ & $78,3 \%$ \\
\hline Junção & 15 & \multicolumn{2}{|c|}{50} & $7,4 \%$ & $85,7 \%$ \\
\hline Alinhamento & 12 & \multicolumn{2}{|c|}{$6^{\circ}$} & $5,9 \%$ & $91,6 \%$ \\
\hline Trinca & 10 & \multicolumn{2}{|c|}{70} & $4,9 \%$ & $96,6 \%$ \\
\hline Rebarba & 6 & \multicolumn{2}{|c|}{$8^{\circ}$} & $3,0 \%$ & $99,5 \%$ \\
\hline Bolhas & $\mathbf{1}$ & \multicolumn{2}{|c|}{90} & $0,5 \%$ & $100,0 \%$ \\
\hline Totais & 203 & \multicolumn{2}{|l|}{-} & $100 \%$ & \\
\hline
\end{tabular}

Fonte: [6]

\section{Etapa 3 - Analise:}

Esta etapa se divide em estabelecer as hipóteses (selecionando as causas mais prováveis) e testar as hipóteses (deduzindo as causas principais entre as mais prováveis). Na primeira, deve ser elaborado um diagrama de Causa e Efeito que contenha todos os elementos que pareçam ter relação com o problema de tal maneira a coletar todo o conhecimento relativo às possíveis causas, para isso são utilizadas informações obtidas na etapa 2(Observação) e descartar os elementos que sejam, claramente, não relevantes. Na segunda, devem ser testados os elementos que tenham grande possibilidade de serem causas, novos planos para apurar o efeito que esses elementos têm sobre o 38 problema, através da obtenção de novos dados ou por meio de experiências. Se possível, reproduzir, intencionalmente, o problema.

Para obter melhores resultados nessa etapa, devem ser seguidas as recomendações descritas abaixo:

- Esta etapa é dividida em duas partes, sendo a primeira a formulação da hipótese e a segunda a verificação da hipótese;

- Um diagrama de causa e efeito deve ser usado para formular as hipóteses, ou seja, todas as causas que forem levantadas neste momento serão hipotéticas e sem fundamento científico;

- A formulação das Hipótese deverá ser conduzida com a participação de todos através da discussão das informações obtidas, utilizando as técnicas de geração espontânea de ideias, "Brainstorming". Devem ser aceitas informações apresentadas de forma arbitrária, pois, em geral, podem trazer algo que não estava sendo percebido, mas logo devem ser filtradas e, se estiverem erradas, certamente serão derrubadas na etapa de verificação;

- Reconhecidas as hipóteses, é necessário colher dados a seu respeito, neste caso podem ser criadas folhas de verificação que permitem colher e registrar ordenadamente os mesmos;

- Neste momento, baseados nos dados coletados a partir de experimentos ou levantamentos, é necessário verificar as hipóteses, observando que a coleta de dados tenha sido feita de acordo com um planejamento eficiente e organizado;

- Verificar as hipóteses é investigar se realmente existe uma relação entre as causas e os seus efeitos e também quantificar, baseando-se em ferramentas como a Análise de Correlação, Diagrama de Pareto, dentre outros;

- Deve-se evitar decidir sobre as causas principais através de votação ou até de uma escolha arbitrária. A causa principal é um são diversos elementos que tem a maior influência sobre o resultado, conclusão essa obtida na aplicação das ferramentas de análise;

- Como um grande número de elementos pode influenciar o resultado de uma maneira ou de outra, em maior ou menor grau, os elementos que requerem atenção maior são aqueles que influenciam fortemente o resultado e não aqueles que influenciam pouco o resultado; 
- As ações corretivas devem ser focadas nestes elementos que atuam fortemente, justificando a necessidade de se investigar bem durante esta fase de análise das hipóteses;

- É possível encontrar evidências das causas pela reprodução intencional do defeito. Entretanto tal reprodução deve ser bem planejada quanto à sua execução, pois existem razões de natureza humana, social ou prática que podem comprometer a veracidade destes resultados.A figura 6 mostra um exemplo de ferramenta utilizada nessa etapa.

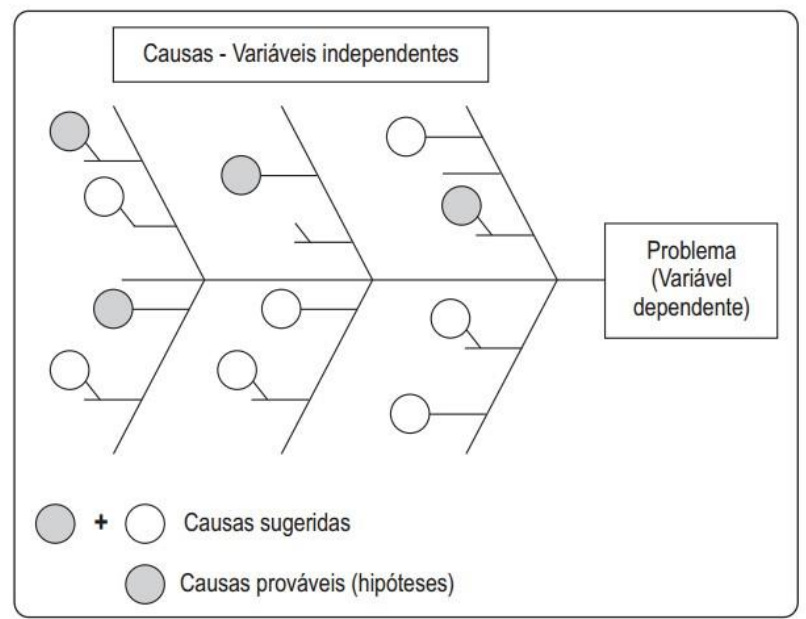

Figura 6: Modelo de Diagrama de Ishikawa Fonte: [5]

\section{Etapa 4 e 5 - Plano de Ação e Ação:}

Uma perfeita distinção precisa ser feita entre as ações tomadas para curar o efeito (remoção do sintoma) e as ações tomadas para eliminar os fatores causadores (prevenção contra o reaparecimento ou bloqueio). Certificar que as ações não produzam outros problemas (efeitos colaterais). Se isso ocorrer, adotar outras ações ou procurar sanar os efeitos colaterais. Idealizar diferentes propostas de ação, examinar as vantagens e desvantagens de cada uma e selecionar aquela que for definida por consenso da equipe envolvida na solução do problema.

Para obter melhores resultados nessa etapa, devem ser seguidas as recomendações descritas abaixo:

- Existem dois tipos de ação. Uma é a ação que atua sobre os efeitos, enquanto a outra é a ação tomada para evitar o reaparecimento do fator causador do resultado. Se for produzido um produto defeituoso é reparado, mesmo que haja sucesso no reparo, o conserto não evitará o reaparecimento do defeito. O modo ideal de resolver o problema é prevenir o seu reaparecimento, adotando medidas para eliminar a causa do problema. Os dois tipos diferentes de ação não podem ser confundidos, adotar sempre procedimentos para eliminar as causas.

- As ações frequentemente causam outros problemas. Elas lembram a aplicação de um tratamento médico que cura uma doença, mas provoca efeitos colaterais que causam outros problemas ao paciente. Para evitar efeitos colaterais, a ação tem que ser avaliada e guiada sob a maior quantidade possível de pontos de vista. Também devem ser executados testes preparatórios. Se houver possibilidade de aparecimento de efeitos colaterais considerar outras ações corretivas ou ações para sanar os efeitos colaterais.

- Um fator prático importante ao selecionar um bloqueio é assegurar a cooperação ativa de todo o pessoal envolvido. Uma ação de ataque a fatores causadores de problemas causará várias mudanças na rotina de trabalho. O bloqueio precisa ter a concordância de todos os envolvidos. Se houver muitas contramedidas possíveis, as vantagens e desvantagens de cada medida devem ser examinadas levando-se em consideração a opinião de todos os envolvidos. Se houver diversas soluções possíveis que atendam igualmente aos quesitos técnicos e econômicos, é melhor selecionar a decisão final, democraticamente. A tabela 3 mostra um exemplo de ferramenta utilizada nessa etapa.

Tabela 3: Exemplo de Plano de Ação baseado no modelo $5 \mathrm{~W} 2 \mathrm{H}$

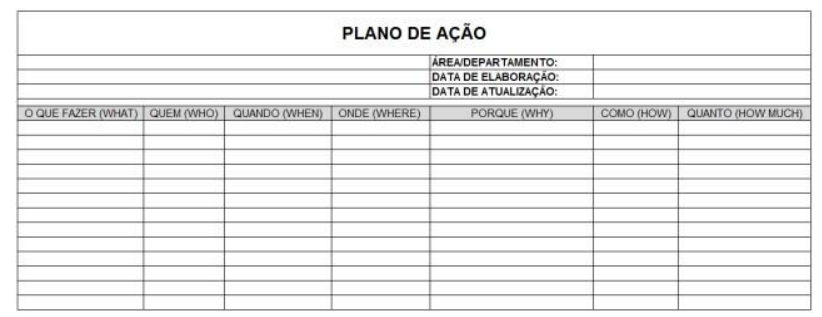

Fonte: [7]

\section{Etapa 6 - Verificação:}

Nessa etapa, deve-se comparar os dados obtidos sobre o problema (resultados indesejáveis) antes e após os bloqueios terem sidos executados. Converter

http: / /dx.doi.org/10.25286/repa.v4i1.887 
os efeitos para termos monetários e comparar o resultado com o valor objetivado.

Para obter melhores resultados nessa etapa, devem ser seguidas as recomendações descritas abaixo:

- Para verificar a efetividade dos bloqueios deveseutilizar os dados coletados antes e após a implementação dos bloqueios. É feita então uma comparação para determinar em que grau os resultados indesejáveis foram reduzidos. O formato usado na comparação (tabelas, gráficos, cartas) precisa ser o mesmo antes e após o bloqueio. Por exemplo, se um Diagrama de Pareto for usado para indicar a situação anterior aos bloqueios, então precisa ser utilizado um Diagrama de Pareto para verificar a eficiência daqueles bloqueios;

- É importante converter os resultados dos bloqueios para valores monetários. Desta forma se faz a medição da contribuição para a lucratividade da Empresa, consequentemente da utilização do MASP.

- Quando o resultado da ação não é tão satisfatório quanto o esperado, certificar que todas as ações planejadas tenham sido implementadas precisamente de acordo com o que foi decidido. Se os resultados indesejáveis continuarem a ocorrer mesmo depois de terem sido executadas as ações, houve falha no processo de solução do problema e é necessário voltar atrás à etapa 2 (observação) para começar outra vez. O gráfico 1 mostra um exemplo de ferramenta utilizada nessa etapa.

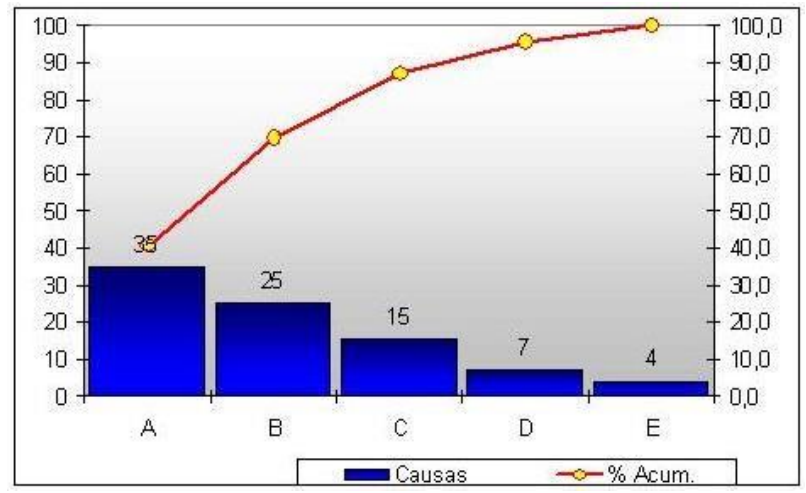

Gráfico 1: Exemplo de Diagrama de Pareto Fonte: [8]

\section{Etapa 7 - Padronização:}

$\mathrm{Na}$ padronização são definidas mudanças que devem ser incorporadas aos procedimentos operacionais ou padrões de rotinas, e posteriormente treinar o pessoal responsponsável para cumprimento dos novos padrões estabelecidos.

Para obter melhores resultados nessa etapa, devem ser seguidas as recomendações descritas abaixo:

- As ações corretivas devem ser padronizadas para prevenir contra o reaparecimento do problema. Há duas razões principais para a padronização. A primeira é que sem padrões as ações executadas para resolver um problema retornarão gradativamente aos antigos modos de trabalho, possibilitando o reaparecimento do problema. A segunda é que o problema pode reaparecer quando novas pessoas (empregados novos, transferidos ou contratados) estiverem envolvidas no serviço. A padronização não é alcançada simplesmente por documentos. Precisam tornar-se uma parte integrante do pensamento e hábitos dos trabalhadores. A educação e o treinamento são necessários para dotar os trabalhadores dos conhecimentos e das técnicas relativas à implantação dos padrões;

- A padronização é uma outra forma de expressar os $5 \mathrm{~W} 2 \mathrm{H}$ para os procedimentos de trabalho. Em alguns casos apenas $\mathrm{O} H$ (como) pode ser contemplado num padrão, em outros pode-se ter padrões somente com quatro $\mathrm{W}$ e um $\mathrm{H}$. O método para execução de um trabalho pode ser bem entendido sem o porquê. Mas o por que é indispensável para a pessoa que executa o trabalho. Há muitas outras formas, além daquela padronizada, de executar um trabalho e obter resultados;

- Por este motivo é que, muitas vezes, um trabalhador não segue o padrão, pois ele não sabe o porquê da necessidade de sua utilização. É por causa disto que o "por que" precisa ser incluído em um padrão. Depois que o pessoal tiver entendido o por quê, os padrões serão cumpridos fielmente. O MASP é uma boa ferramenta para o entendimento do "por quê". Desta forma, os padrões não podem ser separados da MASP que os produziu. Quando o treinamento e a educação para a padronização são ministrados, a Metodologia de Solução de Problemas relativa ao assunto deve ser também estudada;

- A falta da devida preparação e comunicação é uma das principais razões de confusão quando novos padrões são implantados. A implantação de padrões novos muda as rotinas de trabalho e causa confusão produzida por erros triviais; e algumas vezes aparecem problemas, particularmente quando há uma 
divisão do trabalho, se em um local o trabalho é realizado pelo método novo e em outro local ainda é utilizado o método antigo;

- São frequentemente necessários a educação e o treinamento adequados para que os padrões sejam integralmente adotados;

- Às vezes um problema resolvido reaparece inesperadamente. A causa principal disso é que os padrões foram observados no começo, mas permitiuse que o seu cumprimento degenerasse. Um sistema de verificação deve ser estabelecido para garantir o cumprimento constante dos padrões e prevenir contra o reaparecimento dos problemas.

A figura 7 mostra um exemplo de ferramenta utilizada nessa etapa.

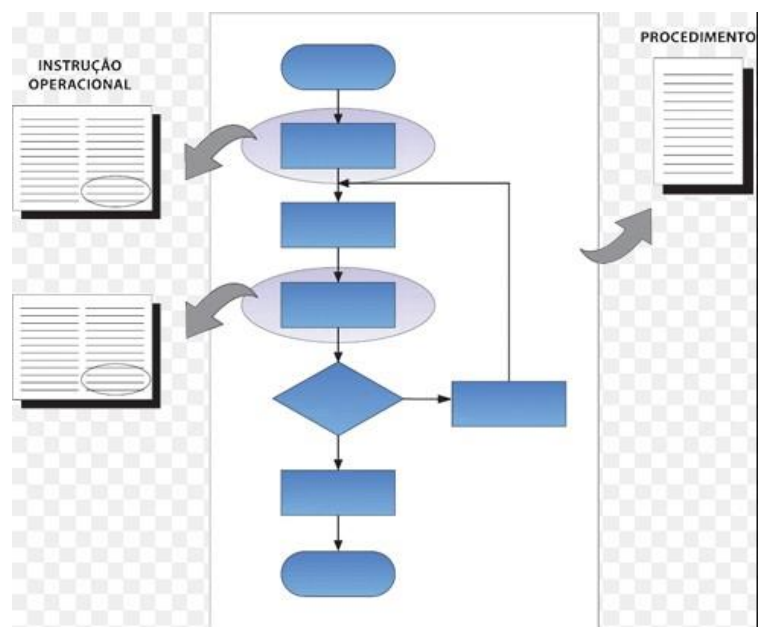

Figura 7: Exemplo de Padronização do Processo Fonte: [9]

\section{Etapa 8 - Conclusão:}

Nessa fase, devemos refletir sobre o que ocorreu de bom e de ruim durante a aplicação do MASP e daí, elaborar o relatório de conclusão do projeto.

Para obter melhores resultados nessa etapa, devem ser seguidas as recomendações descritas abaixo:

- Um problema quase nunca é perfeitamente resolvido e a situação ideal quase nunca existe. Não é conveniente pretender a perfeição ou continuar com as mesmas atividades no mesmo tema por um tempo muito grande. Quando o limite de tempo original é atingido, é importante delimitar as atividades. Mesmo que o objetivo não seja alcançado deve ser feita uma relação da extensão do progresso das atividades e daquilo que ainda não foi alcançado;

- Estabelecer planos sobre o que deve ser feito no futuro com os problemas remanescentes. Os problemas importantes constantes desses planos devem continuar como temas na próxima utilização do Metódo de Análise e Solução de Problemas- MASP;

- Finalmente, alguma reflexão deve ser feita sobre as próprias atividades de solução de problemas. Isto auxiliará no aumento da qualidade das próximas atividades de melhoria. Existe sempre uma diferença entre a atividade que é realmente executada e a atividade mentalmente entendida como tendo sido executada, e estas diferenças devem ser eliminadas uma a uma. Esta revisão deve ser feita mesmo que o problema tenha sido resolvido com sucesso, mas essa atividade reflexiva deve ser realizada com cuidado especial, se a data limite foi ultrapassada e o problema não foi resolvido.

\section{Aplicações e Resultados}

A seguir é possível compreender os passos utilizados para o desenvolvimento do projeto, de forma ordenada e objetiva, consequentemente a contribuição da aplicação do MASP, através dos resultados obtidos.

\subsection{Identificação do Problema}

Com base nos resultados e monitoramento da satisfação dos clientes, foi identificado um elevado índice de reclamações em relação à qualidade intrínseca do serviço da empresa abordada.

Nos 3 anos que antecederam ao projeto, foram registradas 23 reclamações de clientes em relação a qualidade intrínseca do produto (falta parcial, erro no comprimento, troca de bitola e erro dimensional), conforme observa-se no gráfico 2. Com base nessa informação foi estabelecida a meta de reduzir $40 \%$ do número de ocorrências no decorrer de um ano, valor que chegaria a 14 Reclamações de Clientes (RCs). 


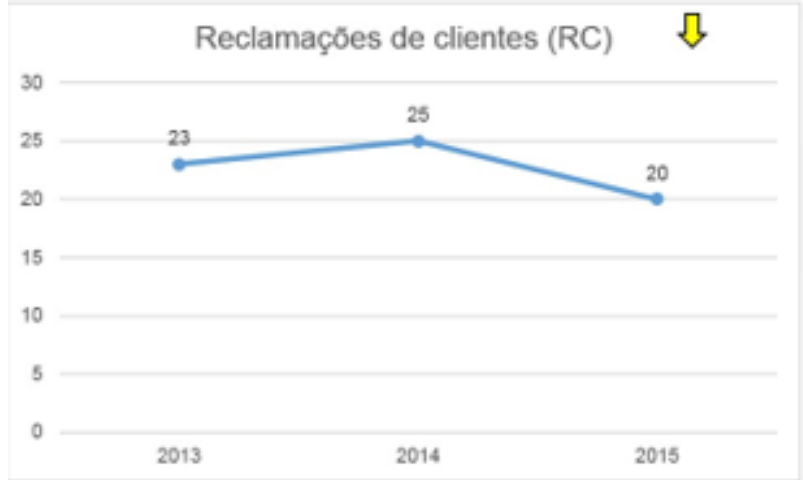

Gráfico 2: Gráfico do IC das reclamações de clientes Fonte: Acervo do autor

Depois de realizados todos as informações e definidas as metas, foi criado o item de controle (IC) Reclamações de Clientes (RC) com o objetivo que toda a equipe do projeto possa acompanhar os resultados obtidos mês a mês.

Após a criação do IC de RC, foi preciso determinar prazos para a conclusão do MASP, para isso foi elaborado o cronograma, de acordo com o gráfico 3, fundamental para que todas as atividades do projeto, não apenas sejam executadas, mas que sejam executadas dentro do prazo.

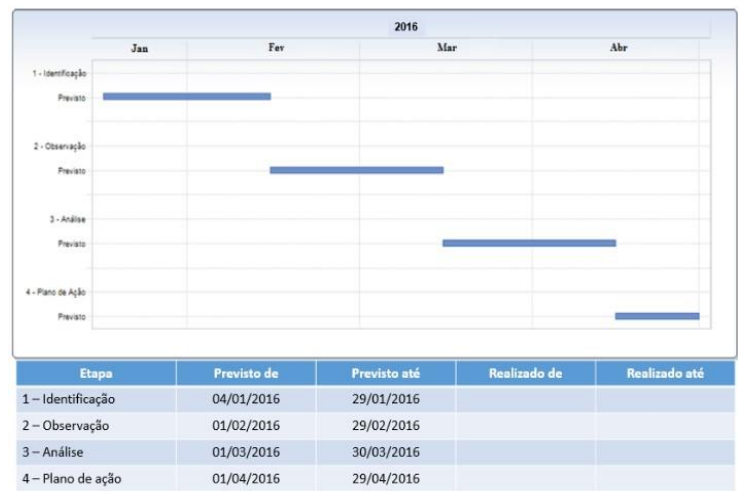

Gráfico 3: Cronograma do projeto Fonte: Acervo do autor

\subsection{Observação do Problema}

Com o problema identificado e metas definidas, a etapa até este momento foi de investigar as características específicas do problema, com diferentes pontos de vista.

Neste momento foi observado no "Gemba" (no chão de fábrica) ações, foi utilizado o método de levantamento de ideías livres, o "Brainstorming", e foram visitados vários clientes para identificar os possíveis problemas que estavam levando ao alto índice de reclamações de clientes na unidade industrial.

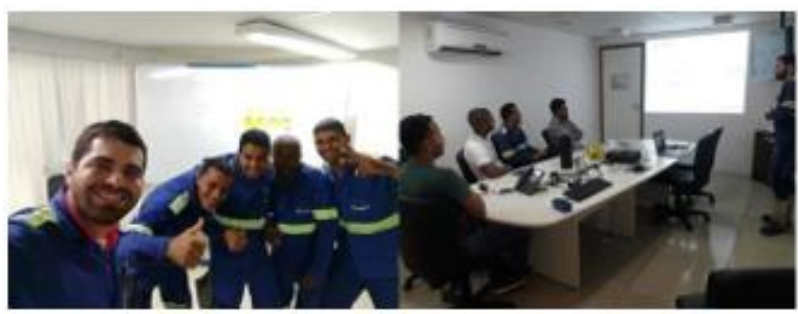

Figura 8: Brainstorming Fonte: Acervo do autor

\subsection{Análise do Problema}

As pistas para resolução do problema estão no próprio problema. Nesta etapa do projeto, foram utilizadas as informações obtidas na etapa de observação para identificar quais as causas fundamentais para o elevado índice de reclamações de clientes. A partir da etapa do "Brainstorming", foram identificadas as causas fundamentais do problema conforme mostra a figura 9.

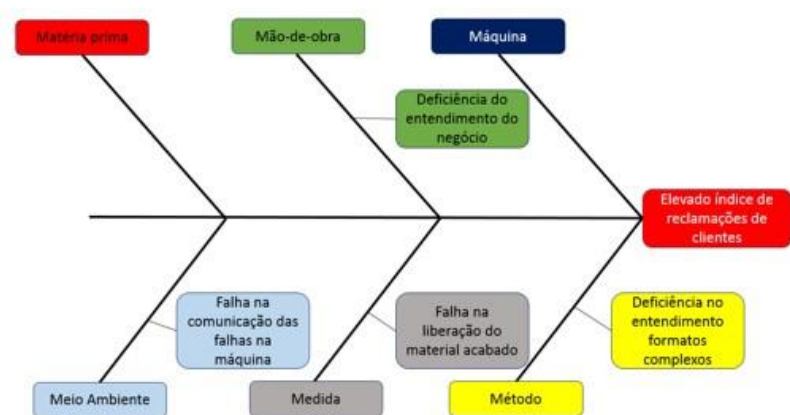

Figura 9: Diagrama de Causa e Efeito Fonte: Acervo do autor

De posse das causas raízes, teve início a elaboração do plano de ação.

\subsection{Planos de Ação}

Existem dois tipos de ações. Aquelas que que são tomadas para curar o efeito, e as que são tomadas para eliminar os fatores causadores. $O$ modo ideal de resolver o problema é prevenir o seu reaparecimento, adotando medidas para eliminar a causa do problema. 
Portanto, o plano de ação para a redução do número de reclamações de clientes foi elaborado por toda a equipe do projeto, como observado na tabela 4, foram definidas ações, seus responsáveis e o prazo para conclusão, com base na análise das causas fundamentais dos problemas.

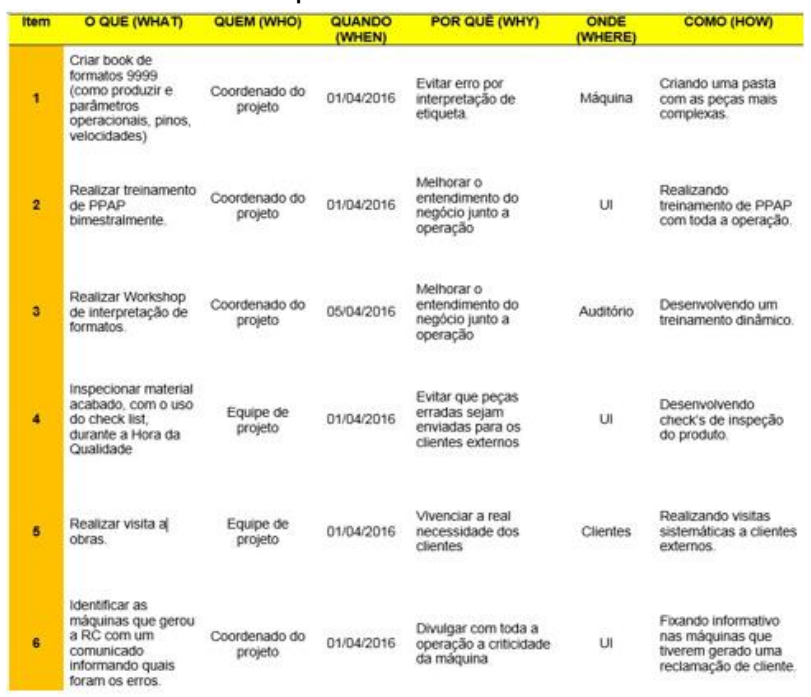

Tabela 4: Plano de Ação Fonte: Acervo do autor

\subsection{Ação}

Com o plano de ação definido, a equipe do projeto iniciou o cumprimento do mesmo. Todas as ações foram cumpridas no prazo acordado. A exemplo do "Workshop" de interpretação de formatos, ilustrado na figura 10 , esse treinamento qualificou a mão de obra da unidade industrial. Já o treinamento de PPAP (Prática de Processo e Aplicação do Produto), ilustrado na figura 11, trouxe para toda a equipe um conhecimento geral de toda a cadeia produtiva até a aplicação do produto. As visitas, ilustrado na figura 12, estreitou os laços e fidelizou os clientes mais estratégicos.

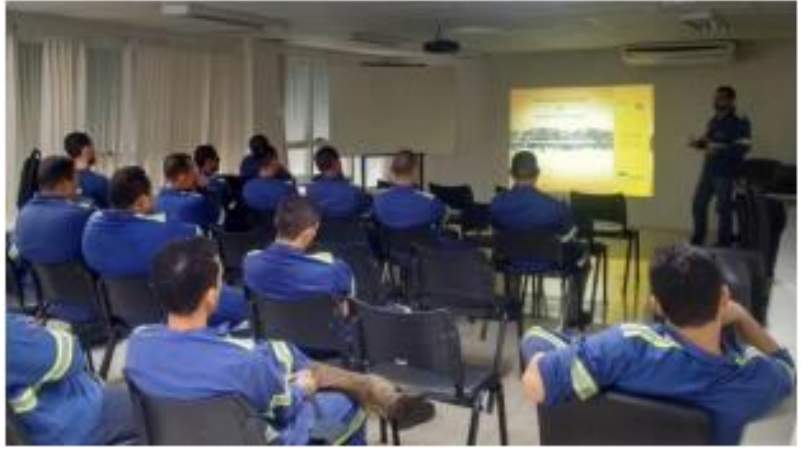

Figura 10: Workshop de interpretação de formatos Fonte: Acervo do autor

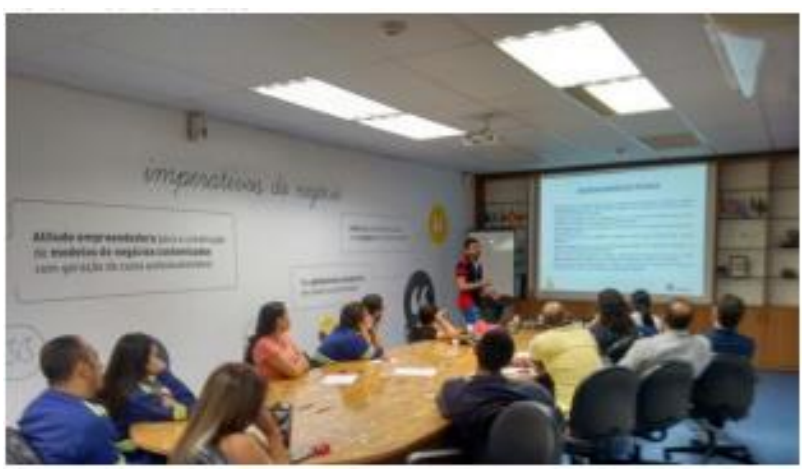

Figura 11: Treinamento PPAP Fonte: Acervo do autor

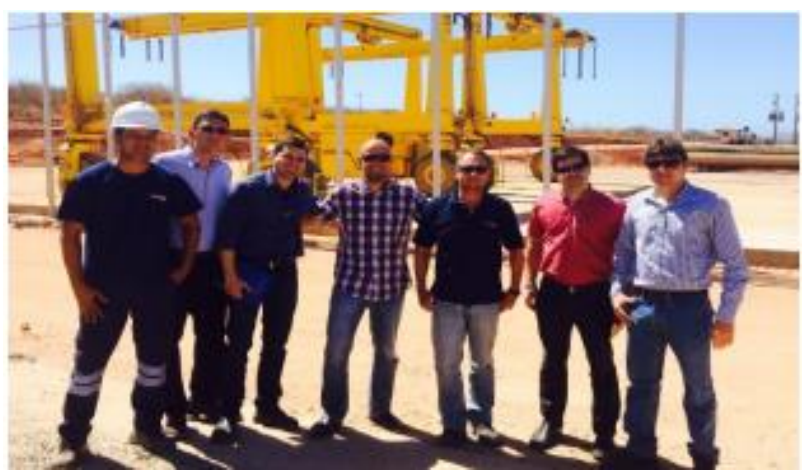

Figura 12: Visita a clientes Fonte: Acervo do autor

\subsection{Verificação}

Após a execução do plano de ação é possível analisar os resultados tangíveis e intangíveis. Conforme é demostrado no gráfico 4, com a implantação das ações, foi possível reduzir o número de reclamações de clientes, demonstrando a eficácia da aplicação do MASP.

http: / / dx.doi.org/10.25286/repa.v4i1.887 


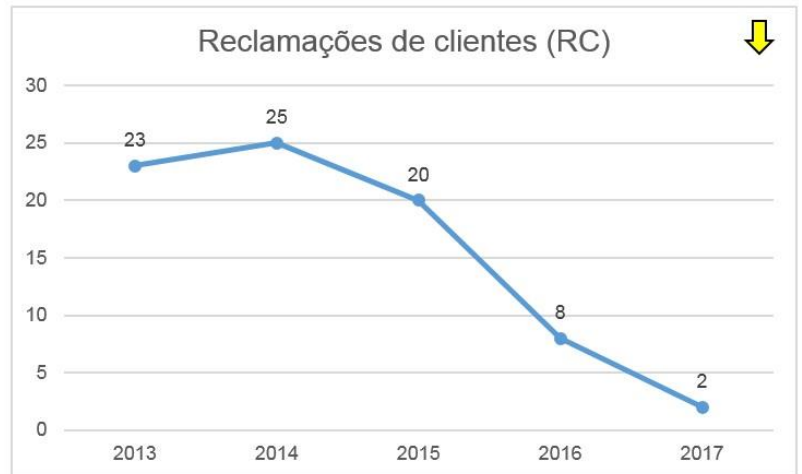

Gráfico 4: Resultado de reclamações Fonte: Acervo do autor

\subsection{Padronização}

Após a verificação da eficácia das ações, foram desenvolvidos Procedimentos Operacionais Padrões (POPs) para todas as atividades de rotina e foram desenvolvidos Q1 (modelo de padronização interno), conforme demonstrado na figura 13, para algumas atividades que necessitavam de uma atenção especial por parte da operação.

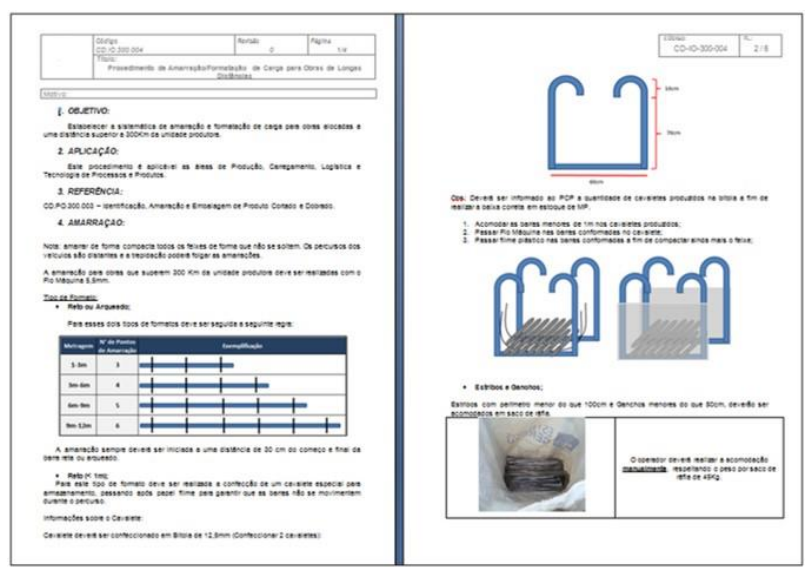

Figura 13: Padronização de embalagem Fonte: Acervo do autor

\subsection{Conclusão}

Avaliando-se os resultados concluir-se que houve sucesso no uso da metodologia, identificando-se a causa raiz, fazendo-se seu bloqueio, desta forma e reduziu-se ao número de reclamações de clientes. A utilização da metodologia permitiu um crescimento técnico e interpessoal no grupo e influenciou todo o processo produtivo.
A unidade que tinha um dos piores resultados do Brasil, em um ano intenso de trabalho, com método, de forma inteligente e persistente, reverteu o quadro e finalizou conforme planejado. Passando de um valor de 23 para 8 reclamações de clientes no ano de 2016 e apenas 2 no primeiro semestre de 2017, demonstrando a eficácia do MASP.

Ficou evidente como o trabalho em equipe de fato faz a diferença para a melhoria de qualquer tipo de processo, o engajamento, a união e a força de vontade das pessoas, superam as as dificuldades no dia a dia. Não são ideias revolucionárias e sim simples ideias e a sinergia de pequenas e grandes melhorias e a evolução destas que garantem o resultado, sempre com excelência por meio da simplicidade.

\section{Considerações Finais}

Este trabalho permitiu avaliar que a metodologia MASP é eficiente, eficaz e efetivo para solução de problemas e a redução do número de reclamações de clientes em uma unidade industrial, neste trabalho comprovou este fato.

Os objetivos do trabalho foram alcançados e concluiu-se que o MASP é uma ferramenta fundamental e útil para se investigar, com evidências objetivas, as causas fundamentais e propor soluções a quaisquer problemas nas organizações. Adicione-se a isso os seguintes ganhos:

- Estabelecer na Organização o MASP como rotina para Solução e Problemas e implementação de Melhorias (Kaizen);

- Método universal para quaisquer área da Organização e quaisquer tipo de empresa;

- Método ajuda a estabelecer trabalho em equipe e obter objetivos e atingimento das metas;

- Traz impacto direto na mudança de mentalidade das pessoas, nos processos e no final contribui para o resultado empresarial;

- É parte da estratégia da Empresa sua implementação continuada e abrangente. 


\section{Referências}

[1] SHINODA. C. A viabilidade de projetos de investimento em equipamentos com tecnologia avançada de manufatura. São Paulo, 2008. 20p. Tese (Doutorado em Engenharia). Escola Politécnica, Universidade de São Paulo, 2008.

[2] Sistema de capacitação Sistema de capacitação interna Indústria do aço. Módulos de capacitação da Sistema de capacitação interna Indústria do aço.

[3] Barros, Luis C. Filho, Kaizen - Material didático disciplina Administração da Produção, Curso Pós Graduação em Gestão da Qualidade e Produtividade - Escola Politécnica -POLI/UPE (2016);

[4] BAZERMAN, Max H. Processo decisório: para cursos de administração, economia e MBAs. 5 ed. Rio de Janeiro: Elsevier, 2004.

[5] CAMPOS, V.F. TQC - Controle da Qualidade Total (no estilo japonês). Belo Horizonte: Ed. INDG Tecnologia e Serviços, 2004.

[6] Site da Kesleygti. Disponível <http://kesleygti.hostoi.com>. Acesso 18 de março de 2017

[7] Site da Scrumex. Disponível <http://scrumex.com.br/blog $>$. Acesso 18 de março de 2017.

[8] Site Blog.Qualyteam. Disponível <http://blog.qualidadesimples.com.br/2013/07/29/passo-a-passo-decomo-fazer-o-diagrama-de-pareto $>$. Acesso 18 de março de 2017.

[9] Site Mundogeo. Disponível <http://mundogeo.com/blog/2009/07/04/a-gestao-da-qualidade-nas-empresas-de-geomatica>. Acesso 20 de março de 2017. 